\title{
Pancreatic-Biliary Ascariasis in an Infant
}

\author{
Roy $\mathrm{K}^{1}$, Das J², Mukherjee $\mathrm{D}^{3}$, Kundu $\mathrm{R}^{4}$
}

\begin{abstract}
Ascaris infestation that too causing biliary obstruction is very rare in infancy even in endemic area. Adult Ascaris diameter $(3-6 \mathrm{~mm})$ is more than the average diameter of CBD in paediatric population, which is $1.27+/-0.67 \mathrm{~mm}$. We are reporting a baby of seven months who presented with conjugated hypebilirubinemia and pancreatitis due to Round Worm in CBD.
\end{abstract}

\section{Introduction}

Ascariasis is the commonest helminthic infection in human. Rarely adult worm from small intestine migrates through the sphincter and enter common bile duct (CBD) or pancreatic duct. High index of suspicion for BA is needed especially in tropical countries. Uncomplicated BA responds well to conservative treatment with vermicide medicine, which can eradicate ascariasis in $84 \%$ to $100 \%$ of cases $^{1}$. The best results are obtained when anthelminthic is accompanied by improved environmental sanitation and health education.

\section{The Case}

Seven month female baby presented with progressive jaundice for two months with high colour urine, pale colour stool, itching and multiple bruises all over the body without any vomiting, abdominal distension or passage of worm in stool. No history suggestive of sepsis or intake of any drug. Soft hepatomegaly of $4 \mathrm{~cm}$ under right costal margin and just palpable spleen was present.

Investigation revealed iron deficiency anaemia, eosinophilia of $10 \%$ (absolute eosinophil count-800), conjugated hyperbilirubinemia and other laboratory values are given in the following table.

Ultrasonography (USG) of abdomen revealed dilated CBD with a linear echogenic structure without acoustic shadow in the lower part (Figures 1a, \& 2) suggestive of ascariasis. Magnetic resonance cholangiopancreatography (MRCP) showed dilated CBD of $9 \mathrm{~mm}$. with linear intraluminal filling defect in lower part of CBD (Figures $1 \mathrm{~b}$ $\& 1 c)$.

The baby was managed conservatively with Albendazole. Anticholinergic drug hyoscine was given to facilitate relaxation of sphincter so that worm can get expelled. On follow up after 6 weeks repeat USG showed no echogenic shadow within CBD. Child became anicteric and biochemical report normalised on follow up.
${ }^{1}$ Dr. Kakali Roy, MBBS, MD, Paediatrics, Senior Resident at All India Institute of Medical Science, Delhi, ${ }^{2}$ Dr. Joydeep Das, MBBS, MD, Assistant Professor of Paediatric Medicine, Institute of Child Health, Kolkata, India, ${ }^{3} \mathrm{Dr}$. Devdeep Mukherjee, MBBS, MD, Senior Clinical fellow of Paediatric Medicine at St Mary's Hospital, Manchester, ${ }^{4}$ Dr. Ritabrata Kundu MBBS, MD, Professor of Paediatric Medicine, Institute of Child Health, Kolkata, India.

\section{Address for correspondence \\ Dr. Kakali Roy \\ Email: kakaliroy.nrs2007@gmail.com}

\section{How to cite}

Roy K, Das J, Mukherjee D, Kundu R. Pancreatic-Biliary Ascariasis in an Infant. J Nepal Paediatr Soc 2017;37(1):98-100.

doi:http://dx.doi.org/10.3126/jnps.v37i1.16501

This work is licensed under a Creative Commons Attribution 3.0 License. 


\begin{tabular}{lcc}
\hline Lab Parameters & Value & Reference range \\
\hline Total serum bilirubin & $8.4 \mathrm{mg} / \mathrm{dl}$ & $<1$ \\
\hline Direct bilirubin & $7.4 \mathrm{mg} / \mathrm{dl}$ & $<0.4$ \\
\hline SGOT & $36 \mathrm{U} / \mathrm{L}$ & $22-63$ \\
\hline SGPT & $42 \mathrm{U} / \mathrm{L}$ & $12-45$ \\
\hline Alkaline Phosphatase & $790 \mathrm{U} / \mathrm{L}$ & $100-150$ \\
\hline Gamma glutamyl transferase (GGT) & $443 \mathrm{U} / \mathrm{L}$ & $5-32$ \\
\hline Albumin & $2.8 \mathrm{gm} / \mathrm{dL}$ & $3.4-4.2$ \\
\hline INR & 1.8 & $U p$ to 1.5 \\
\hline Lipase- & $1200 \mathrm{U} / \mathrm{L}$ & $145-216$ \\
\hline Amylase & $48 \mathrm{U} / \mathrm{L}$ & $30-100$ \\
\hline Cholesterol & $112 \mathrm{mg} / \mathrm{dl}$ & $<200$ \\
\hline
\end{tabular}

INR was normalized following vitamin $\mathrm{K}$ injection.

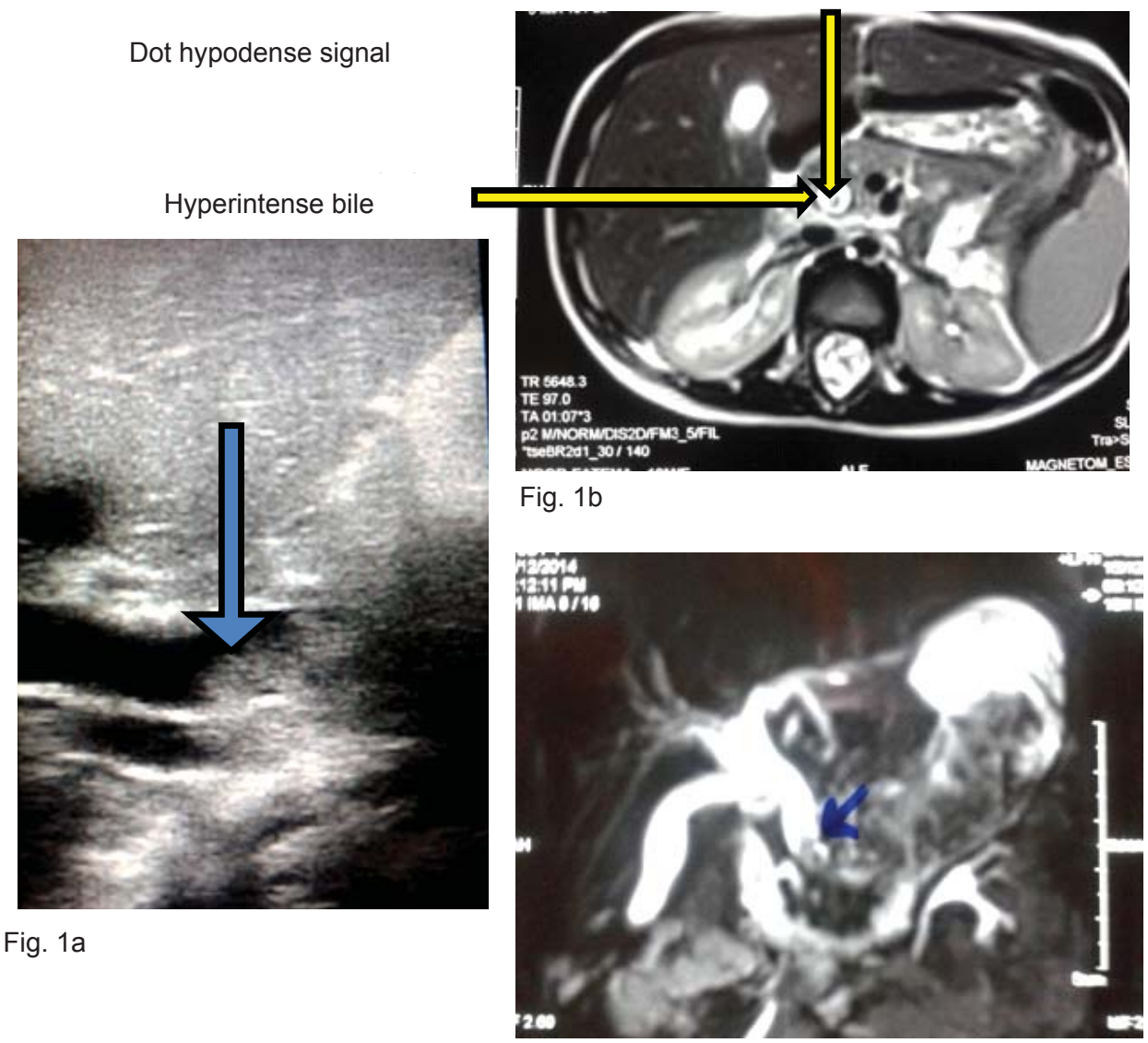

Fig. 1c

Fig.1a: USG showed linear echogenic shadow (shown by arrow) in Common Bile Duct (CBD) without acoustic shadow. Fig 1b:T2 weighted axial image is showing dot hypo intense signal in CBD and around which bile appears hyper intense. Fig1c: MRCP single shot shows linear filling defect in CBD 


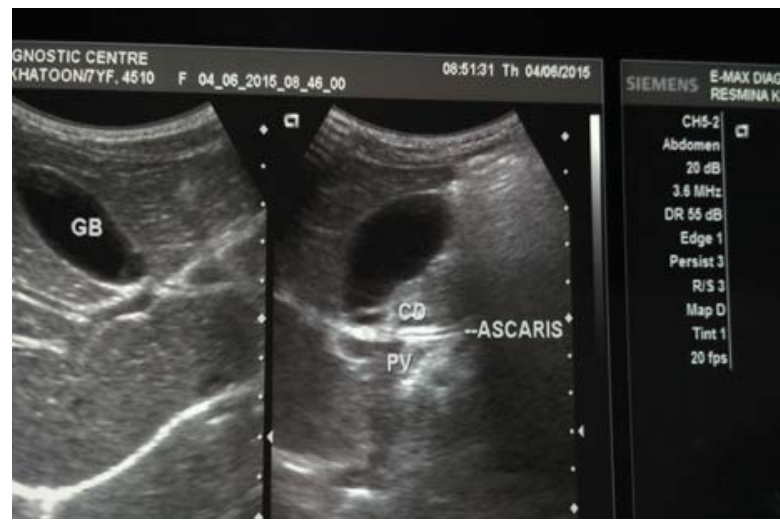

Fig 2: USG is showing gall bladder and $C B D$ and showing linear echogenic shadow in CBD

\section{Discussion}

The prevalence of ascariasis is highest in tropical countries. Intestinal infestation of Ascaris is mostly asymptomatic or cause vague abdominal symptoms. Ascaris infestation that too causing biliary obstruction is very rare in infancy even in endemic area ${ }^{2,3}$. Adult Ascaris diameter (3-6 $\mathrm{mm}$ ) is more than the average diameter of CBD in paediatric population, which is 1.27 $+/-0.67 \mathrm{~mm}^{4}$. Occasional entry of adult worm into the biliary tract results in biliary colic $(56 \%)$ followed by obstructive jaundice, cholangitis, choledocholithiasis, cholelithiasis, acalculus cholecystitis, acute pancreatitis $(6 \%)$ and intrahepatic abscess ${ }^{5}$. Infestation is acquired through ingestion of raw vegetables contaminated with fertilized egg. From ingestion to oviposition by the adult female, it takes two to three months ${ }^{6}$. In our case seven month baby who was exclusively breastfed up to five months of age, most probably got infestation because of very poor sanitation, which is the most important risk factor. Ascaris in lower part of CBD can cause

\section{References}

1. Larrubia JR, Ladero JM, Mendoza JL, Rubio MD. The role of sonography in the early diagnosis of biliopancreatic Ascaris infestation. J Clin Gastroenterol 1996;22:48-50

2. Chakrabarti I, De A, Giri Aet. al. Radio-pathological diagnosis of hepatobiliary ascariasis: A rare entity. $J$ Cytol 2011;28:114-116. doi:10.4103/0970-9371.83468

3. Misra SP, Dwivedi M. Clinical features and management of biliary ascariasis in a non-endemic area. Post Grad Med J 2000;76(891):29-32. doi:10.1136/pmj.76.891.29

4. Hernanz-Schulman M, Ambrosino MM, Freeman PC, Quinn CB. Common bile duct in children: sonographic dimensions. Radiology 1995;195(1):193-5. DOI: https://doi.org/10.1148/radiology.195.1.7892467 obstruction of both CBD and pancreatic duct together, as in our case. Sensitivity of abdominal ultrasonography to diagnose BA is $50-86 \%{ }^{7}$ but it is operator dependent and it is also useful for follow up assessment. Endoscopic ultrasonography is now considered as most sensitive method which can increase the sensitivity of diagnosis. In our case as real time USG did not show any movement and gastrointestinal tract of the Ascaris was not visible, possibly it was a dead worm. MRCP is very effective in detecting intra-ductal ascariasis. ERCP is considered as therapeutic rather than diagnostic measure when conservative management fail. Anthelminthic are given following the procedure to prevent re-entry of worms through papillotomy. Stool examination for egg is not sensitive.

The conservative treatment usually fails in the presence of concomitant stones or stricture which prevents the worm to return in the duodenum. Paralyzing vermicides should be avoided in patients with complete or partial obstruction as the paralyzed worms will not be expelled and may land up in surgery. In a study from Kashmir, which is known as highly endemic area ${ }^{8}$, Conservative management was successful in $88 \%$ of the patients. In our case patient has responded to the medical management and showed no evidence of cholangitis or worm in follow up.

\section{Conclusion}

Biliary ascariasis is extremely rare cause of obstructive jaundice in Infant, even in endemic area. This should be kept in differential diagnosis of infantile cholestasis specifically in the background of poor sanitation and low socioeconomic condition. Good imaging is the main modality of diagnosis.

5. Wani MY, Chechak BA, Reshi F, Pandita S, RatherMH et. al. Our experience of biliary ascariasis in children. $J$ Indian Assoc Pediatr Surg 2006;11:129-132. DOI:10.4103/0971-9261.27240

6. Bethony J, Brooker S, Albonico M, Geiger SM, Loukas A, Diemert D, Hotez PJ. Soil-transmitted helminth infections: ascariasis, trichuriasis, and hookworm. Lancet 2006;367:1521-32. DOI: http://dx.doi. org/10.1016/S0140-6736(06)68653-4

7. Jethwani $U$, Singh GJ, Sarangi $P$, Kandwal V. Laproscopic Management of Wandering Biliary Ascariasis. Case Rep Surg 2012;:1-4. doi: $10.1155 / 2012 / 561563$

8. Mukhopadhyay M. Biliary Ascariasis in the Indian Subcontinent: A Study of 42 Cases. Saudi J Gastroenterol 2009;15(2):121-24 doi: 10.4103/13193767.48970 